\title{
A Insurreição de Eros: sobre a falência da capacidade negativa na cultura
}

\section{contemporânea}

\author{
The Insurrection of Eros: about the ruin of negative capacity in contemporary culture \\ La Insurrección de Eros: sobre la ruina de la capacidad negativa en la cultura contemporánea
}

Recebido: 29/12/2020 | Revisado: 30/12/2020 | Aceito: 03/01/2021 | Publicado: 05/01/2021

Eduardo Dworzecki Pires

ORCID: https://orcid.org/0000-0002-4863-8711 Centro Universitário Metodista, Brasil

E-mail: eduardo.dworzecki.pires@gmail.com

Cleber Gibbon Ratto

ORCID: https://orcid.org/0000-0002-9059-728X Centro Universitário Metodista, Brasil

Universidade LaSalle, Brasil

E-mail: rattocleber@gmail.com

\begin{abstract}
Resumo
Este trabalho desenvolve uma reflexão acerca da cultura contemporânea e dos modos de vida atuais, discutindo sobre algumas das lógicas que não somente organizam a atualidade, mas também que tornam possível uma série de problemáticas de natureza psicossocial. Trata-se de uma pesquisa qualitativa apresentada na forma de ensaio teórico que põe em análise uma cultura marcada pelo impacto das formas atuais do capitalismo em sua face neoliberal. Nesta, há um considerável enaltecimento da felicidade, do prazer, do consumo e da produtividade, de modo que aquilo que escapa ao tempo do capitalismo - como o sofrimento e como a capacidade negativa - deixa de ser valorizado e passa a ser expurgado a qualquer preço. Nesse tempo que postula a felicidade enquanto dever e imperativo, aspectos importantes da existência são desconsiderados em favor de movimentos que encerram a vida nas lógicas do pretenso desenvolvimento econômico. Aponta-se, dessa forma, para a relevância de elementos culturalmente negligenciados como a capacidade negativa e como o sofrimento enquanto ferramentas possíveis na articulação de resistências frente a imposições culturais que cristalizam os modos de ser e de estar no mundo.
\end{abstract}

Palavras-chave: Contemporaneidade; Capacidade negativa; Sofrimento; Cultura.

\begin{abstract}
This work develops a reflection about contemporary culture and current ways of life, discussing some of the logics that not only organize present times, but also that make possible a series of problems of psychosocial nature. It is a qualitative research presented in the form of a theoretical essay that analyzes a culture marked by the impact of the current forms of capitalism on its neoliberal front. In such culture, there is a considerable praise of happiness, of pleasure, of consumerism and of productivity, in order that which escapes the time of capitalism - such as suffering and as negative capability - ceases to be valued and is purged at any price. In this time that postulates happiness as a duty and an imperative, important aspects of existence are disregarded in favor of motions that enclose life in logics of alleged economic development. Thereby it is considered the relevance of culturally neglected elements such as negative capability and suffering as possible tools in the articulation of resistances in face of cultural impositions which crystallize the ways of being in the world.
\end{abstract}

Keywords: Contemporaneity; Negative napability; Suffering; Culture.

\section{Resumen}

Este trabajo desarrolla una reflexión sobre la cultura contemporánea y las formas de vida actuales, discutiendo algunas de las lógicas que no solo organizan la actualidad, sino que también posibilitan una serie de problemas de carácter psicosocial. Se trata de una investigación cualitativa presentada en forma de ensayo teórico que analiza una cultura marcada por el impacto de las formas actuales del capitalismo en su rostro neoliberal. En esta, hay un aumento considerable de la felicidad, el placer, el consumo y la productividad, de modo que lo que escapa a la época del capitalismo - como el sufrimiento y como la capacidad negativa - deja de ser valorado y se depura a cualquier precio. En este tiempo que postula la felicidad como deber e imperativo, se descuidan aspectos importantes de la existencia en favor de movimientos que cierran la vida en la lógica del supuesto desarrollo económico. De esta manera, está en evidencia la relevancia de elementos culturalmente desatendidos como la capacidad negativa y el sufrimiento como posibles herramientas en la articulación de la resistencia frente a las imposiciones culturales que cristalizan las formas de ser y estar en el mundo.

Palabras clave: Contemporáneo; Capacidad negativa; Sufrimiento; Cultura. 


\section{Introdução}

Para vias de compreensão acerca da produção de sujeitos em voga na contemporaneidade, é necessário tomar em análise a cultura na qual tais sujeitos são forjados. Pensar a respeito dos tempos atuais, indubitavelmente, diz respeito a versar sobre a vida em um nó inextricável com um sistema econômico que organiza não somente o tocante das finanças, mas que também acaba por incidir sobre as subjetividades e que, desse modo, torna possível um cenário deveras passível de problematização.

A realidade contemporânea desvela um tempo intimamente relacionado com o consumo e com o enaltecimento do prazer. Como Fortes (2012) pontua, trata-se do hedonismo enquanto premissa cultural, de maneira que o sofrimento, por sua vez, diz respeito a uma instância digna de ser negada. Na cultura de hoje, as experiências de prazer devem ser maximizadas, como também a felicidade acabou por se tornar um dever. Nessa conjuntura, estamos a pensar a respeito de uma "[...] cultura hedonista e psicologista que incita à satisfação imediata das necessidades, estimula a urgência dos prazeres, enaltece o florescimento pessoal, coloca no pedestal o paraíso do bem-estar, do conforto e do lazer" (Lipovetsky, 2004, p. 61). Por conseguinte, trata-se de um tempo no qual, como bem elucida Han (2015), há um excesso de positividade, uma ambiência cultural que, incessantemente, tenta estancar tudo aquilo de negativo ao passo que faz desvanecer todo tipo de alteridade em uma espécie de mácula de ditadura do igual. Nessa realidade do capitalismo financeirizado, as dinâmicas de sofrimento psíquico passam a adotar contornos específicos, tendo em vista que "o desaparecimento da alteridade significa que vivemos numa época pobre de negatividades. É bem verdade que os adoecimentos neuronais do século XXI seguem, por seu turno, sua dialética, não a dialética da negatividade, mas a da positividade. São estados patológicos devidos a um exagero de positividade" (Han, 2015, p.10).

Consequentemente, nessa conjectura, a contemporaneidade delineia um tempo no qual os sujeitos são marcados pela escassez de um elemento ímpar capaz de auxiliar nos trajetos e nas vicissitudes da própria existência: a capacidade negativa. Trata-se, como traz French (2001), da capacidade de viver e de conseguir tolerar a ambiguidade e o paradoxo análogos à experiência, logo, de uma capacidade de manejo das adversidades da própria vida. Entretanto, no tocante do status quo, o que se manifesta está muito mais de acordo com lógicas de silenciamento dos infortúnios do que qualquer outra coisa. Assim sendo, na medida em que padrões culturalmente impostos acabam por favorecer movimentos de normatização da existência, assim como silenciamentos a respeito daquilo culturalmente tomado como negativo, pensa-se na aposta de resistência frente ao modus operandi da cultura por meio da tomada de si mesmo enquanto objeto de criação do próprio viver, movimento esse que envolve assumir, inclusive, aspectos do próprio existir que são culturalmente negligenciados.

Portanto, tendo em vista as problemáticas levantadas, o objetivo deste trabalho diz respeito a pensar sobre como sujeitos forjados no seio de uma cultura marcada pela positividade são destituídos de suas capacidades negativas, assim como ponderar a importância de ofertar atenção a elementos menosprezados nos tempos atuais como via de resistência às moções na cultura, que acabam por fomentar uma ditadura do igual.

\section{Metodologia}

O presente trabalho, considerando o conteúdo e a forma como é apresentado, adota o estilo de um ensaio. Isto posto, o exercício intelectual que se configura como ensaio, nas idiossincrasias análogas ao gênero em questão, apresenta traços singulares, de maneira a orientar uma problematização da cultura vigente a partir do próprio plano da experiência. Tal trabalho compõe uma pesquisa qualitativa manifesta na forma de ensaio teórico, visto que no mesmo "[...] é importante a interpretação por parte do pesquisador com suas opiniões sobre o fenômeno em estudo.” (Soares Pereira et al., 2018, p. 67).

Além disso, a análise de dados e informações segue um método indutivo posto que se navega desde constatações mais particulares até teorias, assim como concerne ao "[...] método que considera o conhecimento como baseado na experiência; a 
generalização deriva de observações de casos da realidade concreta e são elaboradas a partir de constatações particulares." (Soares Pereira et al., 2018, p. 28).

Nessa conformidade, levando em conta a problematização da contemporaneidade em cena, a produção em questão configura-se como um ensaio, visto que estabelece uma relação com o tempo presente e o faz, também, para o presente, não tratando o mesmo como realidade especificamente, mas sim como experiência, logo, trata-se de uma possível forma a uma experiência do presente (Larrosa, 2003; Larrosa, 2004).

Ainda, no tocante ao estilo de produção em questão, o qual dialoga com o contemporâneo, como Gatti (2014, p. 182) pontua, "o ensaio não constrói seus conceitos a partir de um princípio primeiro, de um imediato anterior às mediações, nem reenvia seus objetos, por mediações sistemáticas, a uma totalidade anterior, mas os aborda em seu aqui e agora, como algo formado na cultura". Refere-se a um texto que "[...] trata de desconjuntar o presente, de desnaturalizar o presente, de estranhar o presente, de converter o presente, não em um tema, mas em um problema [...]" (Larrosa, 2004, p. 34). À vista disso, o ensaio articula-se, justamente, a partir do tempo atual para, dessa forma, ir pensando em novas experiências possíveis do presente, em novas possibilidades de ser e de estar no tempo atual.

Por conseguinte, tendo em vista que um dos aspectos do trabalho em questão diz respeito a questionar a atualidade e suas fronteiras, "o ensaio confundiria ou atravessaria a distinção entre ciência, conhecimento, objetividade e racionalidade, por um lado; e arte, imaginação, subjetividade e irracionalidade por outro." (Larrosa, 2003, p. 106). Dessa maneira, tal produção delineia-se como dotada de um caráter mais subjetivo, uma vez que dialoga com um ponto de vista acerca da realidade intimamente relacionada com uma posição discursiva e pensante referente à experiência vivida pelo próprio autor, afinal, “[...] o ensaio é uma atitude existencial, um modo de lidar com a realidade, uma maneira de habitar o mundo, mais do que um gênero da escrita." (Larrosa, 2004, p. 32). Não se trata de um texto em que o autor aparece em primeira pessoa exatamente, uma vez que concerne "[...] um modo de exercício intelectual em que a subjetividade não aparece de modo imediato e espontâneo, mas pelo esforço de trazer à tona as configurações concretas dos objetos sobre os quais ela se debruça." (Gatti, 2014, p. 172). Na medida em que o ensaio apresenta-se como um plano no qual a linguagem coloca-se como fruto de uma relação singular entre a experiência e o pensamento - uma manifestação específica da experiência subjetiva do autor -, tal texto coloca em questão o valor da verdade ao passo em que insiste em afirmar sua própria poeticidade (Larrosa, 2004; Eyben, 2011).

O presente ensaio encontra o sustentáculo de sua gênese a partir de um sentimento de profunda incomodação, por parte do autor, perante a cultura vigente e, em mesma medida, um marcante desejo de ensaiar em si a capacidade e as moções que este trabalho vem a apontar como extenuados na atual época. No que tange ao encontro de tal plano da experiência com a teoria, o ensaio tem o início de seu percurso em uma problematização da contemporaneidade e na exposição de alguns dos paradigmas que a organiza. Na sequência, uma reflexão acerca da capacidade negativa e de como se situam as figuras de alteridade no tempo presente, assim como de alguns elementos culturais em voga que acabam auxiliando na construção da atual conjuntura. Ainda, é dissertado sobre o jogo de forças que opera na cultura e algumas das questões que ajudam a compor o cenário nessa configuração. Finalmente, são abordados alguns movimentos possíveis para vias de resistência frente as imposições culturais, pensando, justamente, na potência correlata a composição de novos modos de ser e de estar no mundo que contraponham o ensejo a cristalização da própria existência fomentado pela atualidade.

Interessa ao trabalho situar-se em um vão entre ciência e arte, partindo da complexidade inerente à vida e ao tempo presente para, dessa forma, ensaiar novas possibilidades de existência no próprio presente. Por intermédio de uma produção que articula uma tensão incessante entre forma e conteúdo em busca da emergência do novo, "o ensaio principia da e na complexidade, começa pelo que tradicionalmente deveria ser um fim: tem início no cerne do problema; sua carta de apresentação é seu próprio nó.” (Noyama, 2009, p. 3). Assim, a partir de um conluio entre memória, pensamento e experiência 
do próprio autor, surge a intenção de construção de um plano mediado pela linguagem capaz de principiar as condições de possibilidade para a emergência de novas experiências do tempo presente.

\section{Contextualizando a Cultura Ocidental Contemporânea}

\subsection{Contemporaneidade, hedonismo e o cansaço de si}

Considerando o intuito de tomar em análise a cultura ocidental contemporânea, é cabível a discussão de certos elementos que acabam por desenhar as condições de possibilidade para a produção de sujeitos característicos do tempo vigente. A discussão acerca de certos paradigmas concernentes ao atual momento cultural revela como as subjetividades encontram-se à mercê de uma série de elementos que as relegam a formas de padecimento psíquico inseparáveis da atualidade.

Passadas já duas décadas desde a virada do século XXI, a contemporaneidade ocidental se mantém-se paulatinamente intrincada de forma inexorável com o sistema de produção neoliberal e, junto disso, caminha uma série de elementos importantes no tocante à vida dos sujeitos que dessa sociedade fazem parte. Como Fortes (2012) bem coloca, o retrato da cultura em voga encontra-se marcado por dois paradigmas os quais muito revelam sobre as lógicas que organizam o mundo atual: o hedonismo e o utilitarismo.

O primeiro destes coloca o prazer, o gozo, como uma questão crucial no que diz respeito à existência humana, de tal forma que os sujeitos detêm o dever de serem felizes. O segundo, por sua vez, apregoa como, na sociedade, uma questão-chave concerne a criação de condições econômicas que abram margem para uma maximização da felicidade. Ainda, uma outra questão atrelada a esses paradigmas remete ao lugar ofertado ao sofrimento. Nesta cultura, o sofrimento é tomado como um mal, digno de ser extirpado e combatido, assim como fonte de vergonha e considerado uma espécie de injustiça para com a existência humana. Por conseguinte, a questão da felicidade encontra-se diretamente ligada ao consumo, uma vez que a obtenção da mesma dar-se-ia a partir da conquista de objetos de bem-estar. Souza et al. (2020) elucidam sobre esse cenário:

O mundo contemporâneo busca a felicidade a todo custo. Vivemos no momento em que somos bombardeados pelo consumismo e somos iludimos que a felicidade se encontra nos bens e nos prazeres passageiros da vida. Sabemos que os bens materiais e os prazeres passageiros não nos satisfazem plenamente. Pois, assim que alcançamos esses bens, no sentido platônico, temos necessidade de outros. (Sousa et al., 2020, p. 5).

Desse modo, operacionaliza-se uma cultura que coloca a felicidade em um pedestal, o qual, para ser acessado, o caminho colocado é o do consumo, de maneira que experiências de prazer acabam se tornando um bem precioso, digno de acumulação e, em contrapartida, o sofrimento é imbuído como uma instância digna de combate (Fortes, 2012). Uma circunstância que ilustra essa desvalorização contemporânea do sofrimento, por exemplo, diz respeito ao lugar cultural ofertado à questão da melancolia, este que se altera ao longo das épocas. Como Amaral et al. (2019, p. 11) colocam: "de lugar de exceção, associado à genialidade e à criação, o sujeito da melancolia passa a ser cerceado pelas teorias psicopatológicas, aprisionado em instituições psiquiátricas, descrito, classificado e categorizado em tratados médicos.”.

Consequentemente, nessa sociedade de consumo que toma a felicidade como uma exigência cultural, não se torna uma tarefa difícil encontrar uma série de ferramentas disponíveis que reiteram a demonização do sofrimento, afinal, a existência de "[...] uma farmacopeia de ansiolíticos, antidepressivos, tranquilizantes, euforizantes desenvolve uma função essencial para regularizar o humor, reduzir o sofrimento, tornar tolerável a existência.” (Berardi, 2005, p. 24). À vista disso, como também aponta Berardi (2005), um produto ímpar do sistema de produção globalizado trata-se de estados mentais, sobretudo aqueles que produzem sensações de excitação, de euforia e de prazer e, junto a isso, está colocada uma realidade que vem ocupando cada vez mais espaço na sociedade: a onipresença das virtualidades. Gradativamente, a percepção humana encontra-se imersa na realidade das telas que, com progressiva facilidade, consegue ofertar experiências de excitação, seja 
pelas redes sociais, seja pelos serviços de streaming, seja pela publicidade, etc. Com a intenção de uma remoção dos efeitos de infelicidade através de ambientes virtuais, a contemporaneidade figura-se absorvida pelas virtualidades que decorrem em ambiências que conseguem provocar um sem fim de excitações. Com o fácil acesso a uma torrente de estímulos, as capacidades de percepção são colocadas em xeque de tal forma que se torna inequívoco "como parecem insossos os estímulos do meio imediato em comparação com aqueles que, berrantes, continuamente cintilam na tela; como fica entediante a rotina de cada um diante de tudo aquilo de excitante que as mídias incessantemente veiculam.” (Türcke, 2010, p. 65).

Aliado a esse modus vivendi contemporâneo, um elemento-chave diz respeito à propaganda. Fortes (2012, p. 41) pontua que "a propaganda não se restringe mais a vender os objetos, pois precisa propor o consumo como um estilo de vida regido pela máxima hedonista de obtenção de prazer.”. Com esse universo cultural em que uma das pautas concerne a fruição de excitações e de experiências de prazer, a propaganda torna-se uma espécie de paradigma na comunicação na sociedade uma vez que, ligada a ela, estão as sensações - a excitação que ela é capaz de provocar. Tratando-se da realidade virtual, por exemplo, articular a melhor propaganda possível de si próprio acabou por despontar como um imperativo, afinal, "[...] quem não chama a atenção constantemente para si, quem não causa uma sensação corre o risco de não ser percebido." (Türcke, 2010, p. 37). Seja por meio das mais diversas substâncias moduladoras do sistema nervoso central, seja por meio das incessantes fugas para o virtual, com as diversas ferramentas para maximização das experiências de excitação e prazer junto a um silenciamento do sofrimento, é notável que o cenário delineado pela contemporaneidade é um em que "[...] o vício se transforma em uma constituição social geral [...]" (Türcke, 2010, p. 12).

Como foi apontado por Freud em 1929/1930 (2010), há quase um século, a questão do sofrimento diz respeito a um elemento que é intransponível e inerente à condição cultural. Nessa medida, moções em prol da mitigação da dor fazem parte da experiência humana por meio dos mais variados recursos. Seja por meio de distrações, seja por meio de substâncias embriagantes, a importância da disponibilidade de recursos para fazer frente ao quão árdua a vida sabe ser coloca-se como uma questão evidente há muito tempo. Muito embora o pai da psicanálise não deixe de salientar a relevância dos meios de atenuação dos dissabores da vida, o mesmo deixa claro: "A satisfação irrestrita de todas as necessidades se apresenta como a maneira mais tentadora de conduzir a vida, mas significa pôr o gozo à frente da cautela, trazendo logo o seu próprio castigo." (Freud, 2010, p. 32). Sendo assim, apesar de "O Mal- Estar na Civilização" ter avisado sobre a punição inerente a qualquer tipo de decisão extremada ou técnica de vida adotada com exclusividade, a contemporaneidade apostou todas as suas fichas na excitação, no prazer e na felicidade mediados pelo consumo, visto que "[...] se o homem freudiano renuncia ao gozo em troca de segurança, na pós-modernidade fica-se com o gozo e abre-se mão da segurança.” (Fortes, 2012, p. 46). Dessa forma, o apontamento de Freud (2010, p. 48) mantém-se com tamanha relevância e sintonia com a época atual que aparenta ter sido escrito recentemente: "É hora de nos voltarmos para a essência desta civilização, cujo valor para a felicidade é posto em dúvida".

Diante disso, uma questão de importante valor no tocante às lógicas que organizam a cultura vigente diz respeito à inexorável relação desta com o sistema de produção neoliberal. Considerando que um elemento ímpar que se encontra articulado com a contemporaneidade refere-se ao capitalismo, este não somente rege aquilo que diz respeito à economia, mas incide, inclusive, de forma refinada sobre as subjetividades. Se, nos tempos freudianos, a marca da sociedade era a repressão, a realidade de proibições oriunda dos valores morais da época deu lugar a uma cultura marcada pela depressão. Atualmente, a prerrogativa de produção e performance em cena na sociedade de consumo coloca os sujeitos em um modus vivendi que preconiza o desempenho profissional, dado que os mesmos são convocados a depositarem parte majoritária de suas energias no trabalho (Han, 2015). Se, outrora, o desejo era digno de ser encoberto em prol da sociedade e de seus valores morais, hoje o mesmo é passível de ser explorado pelas lógicas de desempenho e de produção em questão.

Berardi (2005, p.33) pontua com clareza quando coloca que "o desejo estava fora do capital e atraía forças que se 
distanciavam de seu domínio. Hoje se dá o inverso: o desejo chama as energias para a empresa, para a autorrealização no trabalho. E fora da empresa econômica, fora do trabalho produtivo, fora do business, parece não haver mais nenhum desejo, nenhuma vitalidade.”. Uma outra problemática digna de destaque que se coloca perante os paradigmas que organizam a sociedade de consumo com seu lugar distinto ofertado ao desempenho e ao trabalho é a de que o risco apontado por Freud (2010) acerca da agressividade inerente à condição humana introjetada no processo civilizatório encontra uma considerável ênfase na atualidade, muito embora tal agressividade possa passar despercebida nas lógicas autoexploratórias em vigência.

A perversidade da atual conjuntura reside justamente em que "pessoas exploram a elas mesmas de boa vontade sob a ilusão de realizarem-se. Não é a supressão da liberdade, mas a sua exploração que maximiza a produtividade e a eficiência. Essa é a lógica pérfida que está por baixo do neoliberalismo." (Han, 2018, p. 15, tradução minha). Assim, sob a égide de uma autorrealização no trabalho, o capitalismo promove movimentos de autoexploração articulados com uma sensação de liberdade e realização do próprio desejo no ato de extenuação das próprias energias em benefício do desempenho profissional, ou seja, "a gente faz violência a si mesmo e explora a si mesmo. Em lugar da violência causada por um fator externo, entra a violência autogerada, que é mais fatal do que aquela, pois a vítima dessa violência imagina ser alguém livre.” (Han, 2015, p. 62). Com isso, a produção da crença de que ou se está funcionando de acordo com as premissas de desempenho e performance do sistema neoliberal ou se está fracassando enquanto sujeito fornece o ensejo para uma série de formas de padecimento psíquico inerentes à contemporaneidade. Com demandas etiquetadas como depressão, hiperatividade, burnout, essa sociedade produz sujeitos que acabam cansados de si mesmos na medida em que não conseguem manejar as infindáveis demandas de desempenho. Adoece-se, hoje, por não ser capaz de poder mais e mais (Han, 2015).

Portanto, considerando o cenário com que a contemporaneidade dialoga, a realidade de explícita valorização da felicidade mediada pelo consumo e, em paralelo, de desqualificação do sofrimento torna possível uma série de problemáticas sem precedentes na cultura. Fortes (2012, p. 209) deixa claro quando coloca que "[...] o que interessa no sofrimento é o sentido", porém, na cultura em questão, não se dá margem para uma elaboração ou uma produção em cima do mesmo, afinal, não há espaço para capacidades reflexivas no tempo do desempenho e da performance neoliberal. Perde-se o convite que conduz o psiquismo para trabalhar no diálogo com a adversidade. A lógica da felicidade acaba por esvaziar o sentido da vida em meio a uma cultura que fragmenta o sujeito ao dilacerá-lo perante a transformação de instâncias inerentes à sua condição humana enquanto dignas de silenciamento em prol do prazer, da felicidade e do desempenho. Ademais, conforme essa época atual continuar a preconizar que o debruçar-se sobre os próprios conflitos consome um tempo que não é digno de ser despendido de tal maneira, sujeitos continuarão a rumar para, pouco a pouco, um caminho que revela a incapacidade de habitarem a si mesmos.

\subsection{A Falência da Capacidade Negativa na Contemporaneidade}

Diante da realidade exposta pela cultura na contemporaneidade, apresenta-se como pertinente a reflexão acerca de deslocamentos que visam resistir ao modus vivendi da época vigente. A atualidade revela um tempo em que os sujeitos encontram-se despidos de um elemento capaz de projetar a existência não somente para outros rumos, mas, acima de tudo, contrapor aquilo que encerra a vida nas lógicas vigorantes da sociedade de consumo: trata-se, assim, de algo chamado de "capacidade negativa".

O poeta romântico londrino John Keats, nascido no final do século XVIII, legara, dentre as suas famosas obras, as diversas cartas que escrevera. Em uma destas, mais especificamente uma carta que data de 22 de dezembro de 1817, John as endereça a seus dois irmãos George e Thomas Keats, de forma que expõe a respeito daquilo que ele acreditava como características de um homem de sucesso, sobretudo na literatura. Keats (1899, p. 277, tradução minha) afirma: "[...] eu quero dizer Capacidade Negativa, isto é, quando um homem é capaz de existir nas incertezas, mistérios, dúvidas, sem qualquer busca 
irritadiça por fato e razão.".

O psicanalista inglês Wilfred Bion (2019) é quem resgata tal expressão do poeta romântico para, expandindo além do campo da arte e da literatura, articular características importantes para a figura do analista, pensando, também, naquilo de importância para o paciente. Bion (2019, p. 131) refere-se, literalmente, a "[...] capacidade de tolerar meias verdades, incertezas, mistérios, dúvidas, situações inacessíveis, sem querer alcançar, irritado, um efeito e razão.”, logo, relaciona-se a uma disponibilidade para um diálogo com ambiguidades e angústias que, decisivamente, são inerentes à condição humana. Nessa perspectiva, estamos a falar daquilo que seria o encontro com a experiência do estranho, do infamiliar, ou então com aquilo que Freud (2019) nomeou como unheimlich - uma experiência que provoca profunda sensação de desamparo e de infamiliaridade.

A capacidade negativa, desse modo, está diretamente ligada à habilidade de navegar por esse tipo de vivência desafiadora. French (2001), por sua vez, coloca de uma forma que elucida a potência correlata à capacidade em questão:

Capacidade negativa indica a capacidade de viver com e tolerar ambiguidade e paradoxo, [...] e, portanto, engajar-se de uma maneira não defensiva com a mudança, resistindo ao impulso de meramente reagir às pressões inerentes ao correr riscos. Ela [capacidade negativa] implica a capacidade de integrar estados emocionais e mentais ao invés de dissociar a si mesmo de aspectos da experiência emocional ou tentar apartar-se de tal experiência completamente. Essas capacidades permitem, ademais, identificar os humores e modos de sofrimento do outro [...]. (French, 2001, p. 482, tradução minha).

Entretanto, a realidade contemporânea aponta para uma direção oposta àquilo que estaria de acordo com tal capacidade, uma vez que as lógicas que organizam a sociedade de consumo estão devidamente marcadas por aquilo que é positivo. Ao passo que as premissas que engendram o capitalismo culminam na gestão da vida dos sujeitos e de suas relações, o que se dá é uma cultura que busca excluir a negatividade. Assim sendo, como Han (2017) coloca, tudo acaba sendo nivelado e transformado em objeto passível de consumo na cultura em questão. Na sociedade que constrói uma espécie de produção em série de sujeitos depressivos e fracassados, tudo é comparado a tudo, alinhado a modelos específicos de ser e de estar no mundo, onde prerrogativa do desempenho, da performance, culmina em uma forma específica, bem adaptada, tomada como digna de ser seguida ao longo da vida.

Nessa ótica pró-desempenho, a negatividade não serve, seja manifesta na modulação psicoquímica dos humores, seja na positividade análoga ao excesso de informações estímulos e impulsos que essa sociedade tecnologizada torna possível (Han, 2017). No mundo contemporâneo marcado pela positividade, o Outro, a alteridade, dá lugar a uma espécie de ditadura do Igual. Han (2018) explicita esse cenário quando afirma:

A proliferação do Igual constitui as mudanças patológicas que afligem o corpo social. Este é tornado doente não por recusa ou proibição, mas por hipercomunicação e hiperconsumo; não por supressão e negação, mas por permissividade e afirmação. O símbolo patológico de nossos tempos não é repressão, mas depressão. Pressão destrutiva vem não do Outro, mas de dentro. (Han, 2018, p.1, tradução minha).

Tendo em vista que muitos dos ditames da existência são oriundos de premissas que favorecem a um prosperar do sistema capitalista, este é que oferta os moldes de um modus vivendi específico: tudo deve se igualar à máxima do desempenho e da produção, de forma que tudo, inclusive sujeitos, sejam passíveis de consumo. O que se organiza é uma cultura narcísica a libido investida no eu. Na medida em que o hedonismo é um dos paradigmas que baliza a sociedade, "o outro, como diferente do eu, não existe - ele só existe se corresponde ao ideal hedonista do eu, ou seja, só existe para dar prazer ao sujeito. Nesse contexto, os sujeitos não se relacionam mais com outros sujeitos e sim com objetos” (Fortes, 2012, p. 44).

A habilidade do capitalismo em nivelar tudo a um mesmo plano - o do consumo - aponta não somente para uma relação de descartabilidade com os objetos, mas, sendo assim também com os sujeitos, onde "afirma-se aqui o princípio 
capitalista segundo o qual os seres humanos podem ser reduzidos a meros objetos de troca.” (Fortes, 2012, p. 44). Tendo em vista que há uma convocação pela cultura para que os membros desta se componham enquanto dignos de consumo, a libido acaba sendo investida primordialmente no eu, afinal, demanda-se uma quantidade considerável de energia e de trabalho na composição de uma atrativa imagem de si. A respeito desse cenário, Han (2017) pontua:

Hoje, vivemos numa sociedade que está se tornando cada vez mais narcisista. A libido é investida primordialmente na própria subjetividade. $\mathrm{O}$ narcisismo não é um amor próprio. O sujeito do amor próprio estabelece uma delimitação negativa frente ao outro em benefício de si mesmo. O sujeito narcísico, ao contrário, não consegue estabelecer claramente seus limites. Assim, desaparecem os limites entre ele e o outro. O mundo se lhe afigura como sombreamentos projetados de si mesmo. Ele não consegue perceber o outro em sua alteridade e reconhecer essa alteridade. Ele só encontra significação ali onde consegue reconhecer de algum modo a si mesmo. Vagueia aleatoriamente nas sombras de si mesmo até que se afoga em si mesmo. (Han, 2017, p. 7).

Um outro elemento que contribui na construção do cenário em vigência concerne a cada vez mais profunda relação dos sujeitos com as virtualidades. Em uma perspectiva de convergência entre tecnologias informáticas e tecnologias psicotrópicas que valorizam os estados mentais de felicidade, evidencia-se um cenário em que quanto mais o virtual toma conta mais os laços humanos fragilizam-se. O que a realidade de virtualização da existência produz com o outro, grosso modo, é um movimento de dissolução da alteridade. O mundo digital coloca-se como uma ambiência na qual o eu narcísico encontra a si mesmo, de maneira que o outro com toda a sua corporeidade desaparece - este somente se manifesta enquanto uma presença etérea, fantasmática, unicamente com aquilo que é emitido por intermédio do virtual.

Assim, "somos convidados a amar o (tele)distante. E o distante é o outro sem a físicidade, o odor do corpo, sem o medo e a dor de um ser vivo. O distante é o outro cuja existência não podemos autenticar, a verdade intensiva, a reciprocidade desejante." (Berardi, 2005, p. 20). A onipresença desses outros etéreos, produto daquilo que é emitido pelo mundo digital, ainda que possam ser consideradas como meramente virtuais, apresentam um efeito devidamente real, pois basta que essa virtualidade desapareça, seja pela falta de eletricidade, seja pela falta de bateria no smartphone, para sentirmos, no corpo, de fato: “é apenas agora, no momento de sua ausência, que se mostra o quanto é real aquilo que pretensamente seria somente uma realidade virtual, e o quanto se fez pálido e insosso o aqui e agora.” (Türcke, 2010, p. 46).

Uma outra questão que se sucede com essa presença do outro mediada pelo virtual é uma espécie de aproximação desmedida que acaba por despir a alteridade de seu véu de mistério. Ao passo que o outro vai sendo espetacularizado digitalmente, cada vez mais tornando visível, aproximado, tal outro perde a sua dimensão erótica - que pressupõe assimetria e exterioridade. Como Han (2018) expõe, a proximidade do Outro vai dando espaço para uma presença não intervalada do Igual, provocando uma deserotização, uma desmistificação, conforme a sociedade digital da transparência vai buscando destruir as distâncias e a tensão dialética que é inerente à vida - visto que tudo é nivelado, visibilizado e aproximado.

Um outro ponto que se coloca na questão dessa existência humana paulatinamente grifada pelo mundo digital diz respeito a como algoritmos que organizam os mais diversos serviços e redes sociais facilitam a torrente narcísica em voga. Essa realidade de interconexão e comunicação não facilita encontro com a alteridade, posto que, quanto mais se navega, mais se é alimentado daquilo que vai de acordo com o próprio ego. Em uma espécie de peregrinação virtual narcísica, o eu navega em busca do que confirma a si mesmo, negligenciando tudo o que o contradiz. Nessa aventura de lançar-se em um loop egóico, seguidamente, o virtual está a serviço de uma forma de doutrinamento com as nossas próprias ideias (Han, 2018). Diante disso, quanto mais prospera esse universo virtual em questão, mais o aqui e o agora deixam de brilhar com o frescor de vida, tendo em vista que a realidade que cintila nas telas acaba sendo muito mais excitante e segura em face da angustiante presença assimétrica e corporal de um outro. A provocação de Han (2018) acaba sendo certeira:

Hoje, não mais habitamos a terra poeticamente; nós nos mantemos na zona de conforto digital. Somos tudo, menos 
anônimos ou esquecidos de si. A rede digital habitada pelo ego perdeu tudo que é estrangeiro, tudo que é infamiliar. A ordem digital não é poética; com ela, nós operamos no espaço numérico do Igual. (Han, 2018, p. 62, tradução minha).

Uma das questões-chave no tocante à cultura, segundo Freud (2010), refere-se à problemática da irremediável tensão entre Eros e pulsão de morte implicada na civilização e na vida de cada sujeito: de um lado há a presença de uma força que tenta unir, provocar ligação, e, de outro, uma força que busca a disrupção. Nesse embate entre forças eróticas e forças mortíferas, dada a cultura vigente, as primeiras colocam-se em uma situação de expressiva desvantagem. O quadro pintado pela questão do amor na atualidade apresenta-se como representativo dessa conjuntura.

Hoje, com tamanha a aversão a todo sentimento negativo, o amor situa-se radicalizado em gozo, orientado em uma direção que busca isolar o positivo, o prazer e a excitação. Nesse contexto, vínculos amorosos têm a obrigação de suprir as necessidades de satisfação do gozo, de modo que o melhor relacionamento equivale àquele que é capaz de proporcionar uma maximização daquilo que é prazeroso, numa busca pela ausência de negatividade. Junto disso, está colocada a prática do sexo casual, livre dos "embaraços" de um compromisso mais sério, e facilitada por um sem fim de aplicativos e redes socias, tal prática põe-se como o reflexo do amor que se encontra inserido nas lógicas do consumo e do hedonismo. Posto isso, a dimensão da angústia e do sofrimento no encontro com a alteridade e com o amor são dissolvidas na sociedade de consumo, na qual acabamos por buscar a confirmação de si no outro, permanecendo, desse jeito, "os mesmos" (Han, 2017). Essa sociedade de consumo também fomenta a pulsão de morte inerente à cultura de maneiras específicas como, por exemplo, com o paradigma sacrificial do capitalismo, visto que:

[...] o sujeito do desempenho não aceita sentimentos negativos, o que acabaria se condensando e formando um conflito. A coação por desempenho impede que eles venham à fala. Ele já não é capaz de elaborar o conflito, uma vez que esse processo é simplesmente por demais demorado. É muito mais simples lançar mão de antidepressivos que voltam a restabelecer o sujeito funcional e capaz de desempenho. (Han, 2015, p. 60).

Perante essa realidade de coação de si mesmo, o sujeito que acredita estar gozando da liberdade vai explorando suas próprias energias e capacidades, conduzindo a si em direção à morte. Em virtude das premissas capitalistas em jogo, o risco colocado a cultura, como apontado por Freud (2010), pela agressividade correlata ao humano que acaba se voltando ao eu em função do processo civilizatório pode ser percebido nesse funcionamento auto- expiatório em vigência. Tendo em vista o significativo valor cultural depositado na habilidade de o sujeito conseguir desempenhar cada vez mais - a superação de si -, muitas vezes, o mesmo trilha o caminho da própria degradação, este que abarca diferentes nomenclaturas como depressão e como burnout (Han, 2015). Se outrora competia à religião conceder as diretrizes de uma existência de mortificação de si em prol de uma vida futura, no tocante à época atual, é o capitalismo que assume tal incumbência. Por mais que o sujeito que faz parte desse mundo do imperativo da felicidade tente contornar o negativo e o sofrimento e, em paralelo, otimizar sua produtividade, não há premissa cultural que o proteja de sua própria condição humana: "um sistema que rejeita a negatividade do Outro desenvolve traços autodestrutivos.” (Han, 2018, p. 2).

Um outro elemento que reitera o êxito do eixo da pulsão de morte na cultura, por sua vez, refere-se à temporalidade própria da atualidade. Não somente agimos de maneira acelerada perante o trabalho e a produção, mas também a realidade de influxo do mundo digital é tamanha que "nem o mais distinto intelectual que torce o nariz consegue fechar-se diante dos estímulos de tal modo que o sentido de sua atenção, a escolha dos temas e das palavras, o tempo e o ritmo de seus pensamentos não conseguem permanecer sem ser por eles molestados de alguma forma." (Türcke, 2010, p. 10). Em meio a essa torrente de estímulos e de informações, constrói-se uma temporalidade mortífera que arruína a atenção contemplativa, o saber demorar-se, em favor de uma técnica temporal que se tornou marca de nosso tempo e tomada, inclusive, como motivo de orgulho: o multitasking ou multitarefa. Esta que, segundo Han (2015), não representa progresso civilizatório algum, assinala um 
empobrecimento abissal do plano da experiência.

Com a aceleração em jogo, sujeitos vão perdendo a capacidade de articularem uma experiência continuada de si e, por consequência, do outro, mantendo-se em busca do próximo estímulo capaz de provocar excitação e mortificando o próprio desejo, uma vez que "apenas na medida em que a percepção é capaz de fixar-se em algo, juntar-se a algo, é que ela pode tornar-se uma unidade concreta de experiência [...]" (Türcke, 2010, p. 66).

Portanto, dada a realidade cultural, está posto um cenário deveras tumultuoso no que tange à capacidade negativa, em que "cada um é aproximadamente tão livre para não participar quanto Odisseu era para não sucumbir ao canto das sereias." (Türcke, 2010, p. 14). A contemporaneidade, mediante a premissa da felicidade, do desempenho e do silenciamento do negativo e do sofrer, favorece uma incapacidade de diálogo com o infamiliar, com o unheimlich, ou seja, com a angústia oriunda de situações de ambiguidade, de incertezas, de mistérios, de dúvidas, de meias verdades, enfim, desse espaço aflitivo imanente ao encontro com a alteridade. Esse campo visceral da experiência não encontra um ambiente favorável para sua emergência em uma sociedade inexoravelmente atravessada pelas lógicas do capitalismo. Por meio do princípio da produtividade e da superação de si, a temporalidade da sociedade de consumo não contempla a habilidade de ocupar a si mesmo e também de aproximar-se das mais variadas cores que a existência tem a oferecer. Em vista disso, está posto de lado o caminho de Eros, a travessia para o outro, esta que afirma a condição trágica intransponível do ser humano, posto que efetivamente "é com angústia que se dá a inserção da alteridade no psiquismo do sujeito, possibilitando a via do erotismo." (Fortes, 2012, p.61). Afinal, já é tempo de re-erotizar essa casa mercantil!

\subsection{Guarnecendo Eros na Cultura}

Perante as particularidades do momento contemporâneo, o embate entre Eros e as forças mortíferas revela como este último vem sendo o lado em vantagem nesse conflito que é inerente à cultura. Partindo de uma posição de resistência para com a realidade vigente, é oportuno refletir sobre investimentos que venham a favorecer a face em desvantagem como meio possível para articular a composição de outros modos de vida.

Tendo em vista o cenário contemporâneo, o capital diz respeito a uma modalidade específica de valorização econômica das energias sociais e das energias intelectuais, o que acabou impregnando de forma irreversível o sistema cognitivo, de modo que este, assim como os comportamentos, as motivações e as expectativas, encontra-se grifado de forma singular pela marca do capital. Nessa conformidade, a pauta é menos uma questão de abolir o sistema que está em jogo, mas sim de mantê-lo em movimento, impedindo a sua cristalização, posto que a realidade - marcada por buscas de regularizações do humor e de redução do sofrimento, e também por uma narrativa que postula uma relação entre progresso e felicidade - já se encontra deveras consolidada (Berardi, 2005).

Desse jeito, uma atitude relevante concerne a reflexão acerca de movimentos que favoreçam resistências ao status quo, este com devido potencial adoecedor. Pensando, justamente, em um fortalecimento de moções que favoreçam a vinculação entre os sujeitos - na força de Eros que dá liga à civilização -, um primeiro movimento remete à adoção de uma postura incômoda perante a cultura. A fim de conjecturar outros modos possíveis de existir na atualidade, é indispensável uma boa dose de problematização para com esta. É necessária a coragem de estranhar o presente, assim como manejar ansiedade oriunda de tal estranhamento, enquanto um plano que oferece as condições de possibilidade para a emergência do novo, afinal, "o pensamento deve render-se à negatividade do Outro e proceder para o desconhecido. Do contrário, degenera-se em uma operação positiva que continua o Igual.” (Han, 2018, p. 57, tradução minha).

Nessa medida, deslocamentos que se opõem a uma problematização e estranhamento da cultura acabam por favorecer uma manutenção daquilo que já está dado. Além disso, a adoção de tal postura incômoda, inequivocamente, demanda um diálogo com a negatividade que a época atual não favorece. Perante o postulado da felicidade, do desempenho e da omissão do 
sofrimento e sua negatividade, pouco ensejo há para posturas de contestação daquilo que está colocado em virtude de como "a cultura do 'like' rejeita toda forma de ferimento ou de angústia. Mas qualquer um que busca escapar do ferimento completamente experienciará nada; a negatividade do ferimento habita em toda experiência profunda, em todo insight profundo." (Han, 2018, p. 90, tradução minha).

Um outro valioso passo para vias de fortalecimento da força de Eros na cultura vincula-se a uma ressignificação do sofrimento. Essa realidade articulada com a exigência de uma vida de otimismos e felicidade produz um distanciamento do sujeito para consigo mesmo ao passo que gera um desencontro com as instâncias que operam na contramão da positividade, assim, produzindo carências de sentido para a vida. O sofrimento deixa de ser afirmado como parte integrante da vida para tornar-se uma espécie de apêndice nos trilhos do sistema de produção em voga. Sendo assim, a contemporaneidade perdeu uma dimensão trágica da existência, esta que sabe afirmar o sofrimento como parte da condição humana, ofertando contornos a sua experiência. Levando em conta que o quê, de fato, interessa no sofrimento é o sentido ofertado a ele, não se trata de colocá-lo como uma finalidade na arte de existir, e sim de abraçá-lo, pensá-lo enquanto oportunidade. Isso, sim, diz respeito à composição de uma dimensão trágica: a transmutação da dor em alegria (Fortes, 2012).

Entretanto, esse trabalho de transmutação de instâncias valoradas como negativas na cultura - como a dor e como o sofrimento -, não se opera sem uma capacidade negativa - sem a possibilidade de manejar a angústia, a ambiguidade, o paradoxo, oriundos da experiência da negatividade. Demanda-se uma atualização das narrativas que engendram a questão do sofrimento na contemporaneidade, uma que possa tomá-lo enquanto matéria-prima na composição de "[...] uma cultura jubilosa no debruçar-se sobre a dor de existir." (Fortes, 2012, p. 191). Posto isto, fazer frente a pulsão de morte em voga na época atual, guarnecendo a força de Eros no processo civilizatório, também dialoga com uma ressignificação do próprio corpo. Este que, segundo Le Breton (2012), remete ao lugar privilegiado de contato e experimentação com o mundo, o corpo se traduz como um plano de devida importância que, na contemporaneidade, tornou-se um objeto funcional que serve às lógicas capitalistas.

Hoje, o corpo experimenta-se atravessado pelo imperativo neoliberal da performance, de maneira que, reduzido a objeto, o mesmo se torna passível de uma série de técnicas corporais, como as provindas do mundo fitness, pensado justamente enquanto um objeto digno de otimização para que seu desempenho seja cada vez mais aproximado a de uma máquina (Han, 2018). Com essa lógica de autocoação, é como se o corpo que outrora foi vítima da introjeção da culpa cristã, como colocado por Nietzsche (1998), atualmente se encontra vítima de uma autoflagelação pró performance. Nessa medida, está colocada a demanda para a emergência de um outro corpo, um que seja tanto corajoso, quanto transgressor.

Trata-se de um corpo que transgride as premissas de produtividade em questão para, com capacidade negativa, adotar a corajosa posição de suster uma atenção contemplativa, inclusive, perante a angústia abissal do infamiliar. Nessa perspectiva, resistir a essa cultura requer a composição de um corpo, como traz Nietzsche (1998), com qualidades bovinas, capaz de ruminação, isto é, que seja capaz de uma atenção profunda contemplativa que se localiza justamente na contramão das demandas de hiperatividade e da aceleração produtiva em vigência. Sobre a riqueza acerca de tal tipo de atenção, Han (2015) pontua:

Os desempenhos culturais da humanidade, dos quais faz parte também a filosofia, devem-se a uma atenção profunda, contemplativa. A cultura pressupõe um ambiente onde seja possível uma atenção profunda. Essa atenção profunda é cada vez mais deslocada por uma forma de atenção bem distinta, a hiperatenção (hyperattention). Essa atenção dispersa se caracteriza por uma rápida mudança de foco entre diversas atividades, fontes informativas e processos. (Han, 2015, p. 21).

Uma recomposição da narrativa e da relação que involucra o corpo na contemporaneidade nessas vias está diretamente ligada a uma nova forma de contato com o mundo, na qual há possibilidade de exercício de uma capacidade 
negativa. Logo, de uma postura trágica que entende o sofrimento enquanto parte integrante da existência, capaz de transmutar o mesmo em alegria ou então, como diria o Zaratustra de Nietzsche (2020, p. 134): "resgatar o passado e transformar cada 'assim foi' em 'assim eu o quis!' - é o que eu chamo de redenção!’. Diante disso, guarnecer a força eliciadora de vínculos de Eros na cultura relaciona-se com a construção de um corpo que saiba deixar emergir "[...] o mal-estar específico no qual um organismo pensante é colocado diante de todos os fenômenos que lhe aparecem como inadequados, enigmáticos ou não solucionáveis pelo pensamento, tirando-lhe do repouso, roubando-lhe a certeza e incitando-o a restabelecê-los por meio do pensamento." (Türcke, 2010, p. 90).

Esses movimentos dialogam com uma aposta na experiência e no manejo das intensidades da vida sem uma demonização a priori de certas experiências. Transcendendo a valoração negativa dos elementos que se atravessam no caminho da pungência econômica, abrindo-se para os contornos do trágico - que em nada tem a ver com produtividade -, evoca- se a produção da alegria:

Não há como se viver a alegria de uma forma intensa sem se viver também a dor de uma forma intensa. No sofrimento não se encontram apenas trevas, havendo nele igualmente o encontro da luz, de uma certa sabedoria, da compreensão da própria humanidade e da humanidade alheia, o vislumbre de algumas dimensões da existência que só na dor conseguem mostrar sua preciosidade. (Fortes, 2009, p. 176).

Portanto, guarnecer a posição de Eros na cultura refere-se a uma aposta na negatividade inerente à presença abissal do outro como forma de fazer frente a uma atualidade narcísica. Uma aposta não somente na capacidade negativa, mas na competência criadora do humano capaz de transmutar o sofrimento em alegria: "Criar — é a grande redenção do sofrimento e alívio da vida. Mas para que o criador surja é necessário o sofrimento em si próprio e muitas transformações." (Nietzsche, 2020, p. 79). Em vista disso, desimpedir a manifestação da vida nas suas mais variadas cores e intensidades é colocar em xeque muito das lógicas presentes na sociedade de consumo, estas que preconizam modos de ser e de estar dotados de um ensejo à mortificação. Abrir-se, inclusive, para o sofrimento e para a angústia oriunda do infamiliar põe-se como uma espécie de ode a Eros, um encontro com a experiência visceral da vida em sua carnalidade, que demarca a escolha do abandono de uma felicidade hedonista em prol de uma alegria trágica.

\section{Considerações Finais}

A atualidade e sua relação intrínseca com as lógicas do capital não se anuncia como uma conjuntura que sofrerá contestação de seu modus operandi. O engodo capitalista com a promessa de que o consumo é a chave para a felicidade e a razão do existir humano ainda seduz com proficuidade nessa fábrica do ensimesmamento. Entretanto, de modo algum, ausentase a possibilidade de resistência a padrões culturalmente impostos.

O modus vivendi contemporâneo manifesta-se de uma forma singular: incapacitando sujeitos no tocante do manejo da negatividade, da dor, do sofrimento, visto que a temporalidade que esses elementos demandam não combina com o sistema de produção neoliberal. A época atual é balizada pelas premissas de um capitalismo financeirizado, no qual estas incidem de tal forma sobre a sociedade que tudo é nivelado ao plano do consumo - inclusive, sujeitos. Com isso, a força de Eros na cultura a potência erótica que liga os sujeitos - enfrenta uma posição delicada perante a presença desmedida de forças que modificam o eu em prol do consumo e da produtividade.

Frente esse universo da valorização da felicidade e do gozo, abre-se mão da potência "virtual" resguardada na transmutação do sofrimento em alegria. Problematizar tal realidade nessa perspectiva vincula-se, assim, a uma aposta em moções re-erotizantes - em insurreições de Eros - por meio de uma travessia trágica pela via doloris, em que, mediante capacidade negativa, há o ensejo para a emergência de caminhos que favoreçam o abandono de uma posição narcísica, o cessar 
desse cansaço de si, afinal, "somente Eros é capaz de libertar o eu da depressão, do enredamento narcísico em si mesmo." (Han, 2018, p. 67, tradução minha).

Logo, apontar para a relevância da capacidade negativa e de elementos culturalmente negligenciados como o sofrimento é, acima de tudo, uma aposta na importância da presença abissal do outro capaz de fazer ruir os aprisionamentos em si mesmo fomentados pelo modus vivendi em questão. Ademais, está posto o desafio de ensaiar outras formas de existência, em suma, modos de ser e de estar no mundo dotados de uma coragem para transmutar esse nojo do demasiado humano em uma celebração da vida nas suas mais variadas cores.

Como continuidade do presente trabalho está a proposta de um olhar mais atento para elementos intimamente relacionados a esse tempo de falência da capacidade negativa. A própria questão da paulatina e inexorável relação dos sujeitos com as virtualidades é digna de pormenorizada atenção, considerando que, cada vez mais, a existência encontra-se condensada em uma interação com telas. Assinala-se, dessa forma, a esperança de que trabalhos vindouros contribuam no ensaio de modos existência que abram margem para insurreições de Eros em uma atualidade que insiste no aprisionamento do eu em si mesmo.

\section{Referências}

Amaral, J., Michaelsen, T., \& Carlesso, J. (2019). Melancolia: Arte, Ciência e História no ocidente. Research, Society And Development, 8(5). https://doi.org/10.33448/rsd-v8i5.941

Berardi, F. (2005). A fábrica da infelicidade: trabalho cognitivo e crise da new economy. Dp\&a.

Bion, W. (2019). Capacidade Negativa (Negative Capability). In: A. Chuster, ed., Capacidade Negativa: um caminho em busca da luz, (1st ed.) Zagoboni.

Eyben, P. (2011). AnArquia do Ensaio: (entre experiência e desastre). Alea, 13(2), 283-300.

Fortes, I. (2012). A Dor Psíquica. Companhia de Freud.

French, R. (2001). "Negative capability": managing the confusing uncertainties of change. Journal Of Organizational Change Management, 14(5), 480-492.

Freud, S. (2010). O mal estar na civilização, novas conferências introdutórias à psicanálise e outros textos. Companhia das Letras.

Freud, S. (2019). O infamiliar [Das Unheimliche]. Autêntica Editora.

Gatti, L. (2004). Como escrever?: ensaio e experiência a partir de adorno. Departamento De Filosofia Da Universidade Federal De São Paulo, 35(23), 161187.

Han, B. (2015). Sociedade do cansaço. Editora Vozes.

Han, B. (2017). Agonia do Eros. Editora Vozes.

Han, B. (2018). The Expulsion of the Other: society, perception and communication today. Polity Press.

Keats, J. (1899). The complete poetical works and letters of John Keats. Internet Archive. https://archive.org/stream/completepoetical00keatrich?ref=ol\#page/276/mode/2up.

Larrosa, J. (2003). O ensaio e a escrita acadêmica. Educação \& Realidade, 28(2), 101-115.

Larrosa, J. (2004). A Operação Ensaio: sobre o ensaiar e o ensaiar-se no pensamento, na escrita e na vida. Educação \& Realidade, $29(1), 27-43$.

Le Breton, D. (2012). A Sociologia do corpo. Petrópolis.

Lipovetsky, G. (2004). Os tempos hipermodernos. Editora Barcarolla.

Nietzsche, F. (1998). Genealogia da Moral: uma polêmica. Companhia das Letras.

Nietzsche, F. (2020). Assim falou Zaratustra: um livro para todos e para ninguém. Martin Claret.

Noyama, S. (2009). Adorno e “O ensaio como forma”. Academia. https://www.academia.edu/12210205/Adorno_e_O_ensaio_como_forma.

Soares Pereira, A., Moreira Shitsuka, D., Parreira, F., \& Shitsuka, R. (2018). Metodologia da pesquisa científica [Ebook] (1st ed.). https://repositorio.ufsm.br/bitstream/handle/1/15824/Lic_Computacao_Metodologia-Pesquisa-Cientifica.pdf?sequence=1 .

Sousa, P., Moreira, K., Moreira, H., Sousa, J., \& Salgado, J. (2020). Conceito de felicidade em Sponville. Research, Society And Development, 9(9). https://doi.org/10.33448/rsd-v9i9.7788

Türcke, C. (2010). Sociedade excitada: filosofia da sensação. Editora da Unicamp. 